\title{
Desempenho de Sistema Combinado Anaeróbio-Aeróbio na Remoção de Nitrogênio no Tratamento de Esgoto Sanitário
}

\section{Performance of Combined Anaerobic-Aerobic System in Removal of Nitrogen in the Treatment of Sanitary Sewage}

\author{
Mário Luiz Rodrigues Foco; ${ }^{1}$ Edson Aparecido Abdul Nour ${ }^{2}$
}

\begin{abstract}
Resumo
Este trabalho relata a avaliação do desempenho de um sistema anaeróbio-aeróbio constituído por filtro anaeróbio seguido de biofiltro aerado submerso operado sem e com recirculação do efluente tratado para amenizar os efeitos desfavoráveis das concentrações de matéria orgânica sobre a nitrificação e propiciar posterior remoção do Nitrogênio Total em ambiente anóxico. Nas duas primeiras etapas a taxa de carregamento orgânico (TCO) aplicada no BAS variou entre $0,49 \pm 0,27$ e $0,31 \pm 0,08 \mathrm{~kg} \mathrm{DBO} \mathrm{m}^{-3} \mathrm{~d}^{-1}$ devido à redução da taxa de aplicação superficial (TAS) de 60 para $44 \mathrm{~m}^{3} \mathrm{~m}^{-2} \mathrm{~d}^{-1}$. Na terceira etapa, com recirculação, a TCO e a TAS foram de $0,29 \pm 0,02 \mathrm{~kg} \mathrm{DBO} \mathrm{m}^{-3} \mathrm{~d}^{-1}$ e $65,8 \mathrm{~m}^{3} \mathrm{~m}^{-2} \mathrm{~d}^{-1}$, o que permitiu ao sistema reduzir $43 \pm 10 \%$ da concentração inicial média de $72 \mathrm{mg} \mathrm{L}^{-1}$ de Nitrogênio Total. A aplicação de taxa de carregamento orgânico no BAS, superiores a $0,30 \mathrm{~kg} \mathrm{DBO} \mathrm{m}^{-3} \mathrm{~d}^{-1}$ inibe a nitrificação devido à competição por oxigênio.

Palavras-chave: Filtro Anaeróbio. Biofiltro Aerado Submerso. Nitrificação. Biomassa Aderida.
\end{abstract}

\begin{abstract}
This paper describes the evaluation of the performance of an anaerobic-aerobic system, consisting of anaerobic filter (AF) followed by biological aerated filter (BAF), operated with and without recirculation of treated effluent to mitigate the adverse effects of organic concentrations on nitrification and promote the removal of Total Nitrogen in anoxic ambient. In the first two steps, the application of the organic loading rate (OLR) on BAF ranged from $0.49 \pm 0.27$ and $0.31 \pm 0.08 \mathrm{~kg} \mathrm{BOD} \mathrm{m}^{-3} \mathrm{~d}^{-1}$ due to the reduction of surface application rate of 60 to $44 \mathrm{~m}^{3} \mathrm{~m}^{-2} \mathrm{~d}^{-1}$. In the third stage, with recirculation, OLR and surface application rate were $0.29 \pm 0.02 \mathrm{~kg} \mathrm{BOD} \mathrm{m}^{-3} \mathrm{~d}^{-1}$ and $65.8 \mathrm{~m}^{3} \mathrm{~m}^{-2} \mathrm{~d}^{-1}$, allowing the system to reduce 43 $\pm 10 \%$ of average initial concentration of $72 \mathrm{mg} \mathrm{L}^{-1}$ Total Nitrogen. The application of organic loading rates in BAS, more than $0.30 \mathrm{~kg} \mathrm{BOD} \mathrm{m}^{-3} \mathrm{~d}^{-1}$ inhibited nitrification due to competition for oxygen.
\end{abstract}

Key words: Anaerobic Filters, Aerated Submerged Biofilter, Nitrification, Sewage, Attached Biomass.

\footnotetext{
1 Doutorando em Engenharia Civil - Saneamento e Ambiente, Universidade Estadual de Campinas - Unicamp; foco_mario@ yahoo.com.br

2 Professor Associado do Departamento de Saneamento e Ambiente da Faculdade de Engenharia Civil, Arquitetura e Urbanismo - Unicamp; ednour@fec.unicamp.br
} 


\section{Introdução}

Nos processos anaeróbios, o principal efeito sobre o nitrogênio orgânico é sua hidrólise a nitrogênio amoniacal. Esse composto, além de ser tóxico para algumas espécies aquáticas, ao atingir o corpo receptor exercerá demanda por oxigênio, já que no ambiente aquático pode ser oxidado para nitrito e nitrato, no processo conhecido como nitrificação (HAGOPIAN; RILEY, 1998).

Em um sistema combinado anaeróbio-aeróbio, poupa-se a depleção de oxigênio dissolvido no corpo receptor, porém, a nitrificação não resulta na remoção do nitrogênio do meio líquido, uma vez que os produtos da reação são compostos nitrogenados solúveis. Quando descartados em corpos de água, tornam-se nutrientes disponíveis para algas e plantas aquáticas, sendo os principais responsáveis pela degradação da qualidade das águas de lagos e represas.

A remoção biológica de nitrogênio se dá pelos processos sequenciais de nitrificação e desnitrificação. Na nitrificação, bactérias autotróficas realizam a oxidação de amônia para nitrito e, posteriormente, nitrato. Esse processo requer a presença de oxigênio dissolvido e, portanto, só é possível em ambiente aeróbio. Na desnitrificação, nitrato ou nitrito são reduzidos a nitrogênio molecular, utilizando material orgânico como redutor e bactérias heterotróficas mediando o processo em ambiente anóxico.

Neste contexto, o presente trabalho propõe o estudo de um sistema combinado anaeróbio-aeróbio, constituído por filtro anaeróbio (FA) seguido de biofiltro aerado submerso (BAS), com recirculação do efluente tratado para a entrada do reator anaeróbio (FA), possibilitando assim a desnitrificação nesta unidade, e consequente remoção de Nitrogênio Total do esgoto sanitário.

\section{Materiais e Método}

O presente trabalho teve a intenção de monitorar a redução da matéria orgânica e Nitrogênio Total em sistema combinado anaeróbio-aeróbio, utilizando reatores com leito fixo e escoamento ascendente: filtro anaeróbio (FA) seguido de biofiltro aerado submerso (BAS). O esquema da instalação é apresentado na Figura 1.

As unidades do sistema foram montadas utilizando 2 reservatórios de PVC, constituindo o FA e o BAS, respectivamente, este último possui um difusor de ar no interior do fundo falso, fornecendo aeração necessária para o metabolismo de bactérias heterotróficas e autotróficas em co-corrente com a alimentação do sistema. Um rotâmetro controla a vazão de ar fornecida por um compressor ao BAS.

Ambos os reatores utilizaram eletrodutos corrugados de PVC como suporte de imobilização da biomassa, com 25,4 mm de diâmetro, 15,0 mm de comprimento e índice de vazios de 93,2 $\pm 0,28 \%$. As dimensões das unidades do sistema combinado anaeróbio-aeróbio estão apresentadas na Tabela 1 .

Tabela 1 - Dimensões dos reatores do sistema combinado anaeróbio-aeróbio

\begin{tabular}{lccc}
\hline Dimensões & Unidade & $\begin{array}{c}\text { Filtro } \\
\text { Anaeróbio }\end{array}$ & $\begin{array}{c}\text { Biofiltro } \\
\text { Aerado } \\
\text { Submerso }\end{array}$ \\
\hline Altura & $\mathbf{m}$ & 0,40 & 0,40 \\
Diâmetro & $\mathbf{m}$ & 0,39 & 0,29 \\
Ärea & $\mathbf{m}$ & 0,12 & 0,07 \\
Volume Total & $\mathbf{L}$ & 47,7 & 26,4 \\
Volume Util & & 32,6 & 17,6 \\
\hline
\end{tabular}

Fonte: Autor.

O esgoto sanitário empregado era proveniente do complexo de saúde da universidade no qual circulam aproximadamente 10 mil pessoas diariamente.

O esgoto afluente foi coletado diariamente a partir de um tubo de inspeção e limpeza da rede coletora de esgoto e, encaminhado para o reservatório de alimentação do sistema apresentado na Figura 1. 
Nos pontos 1, 2 e 3 (Figura 1) foram coletadas as amostras que representam, respectivamente, o esgoto bruto afluente ao sistema, o efluente do filtro anaeróbio e do biofiltro aerado submerso.

Figura 1 - Esquema da instalação e localização dos pontos de amostragem de efluente

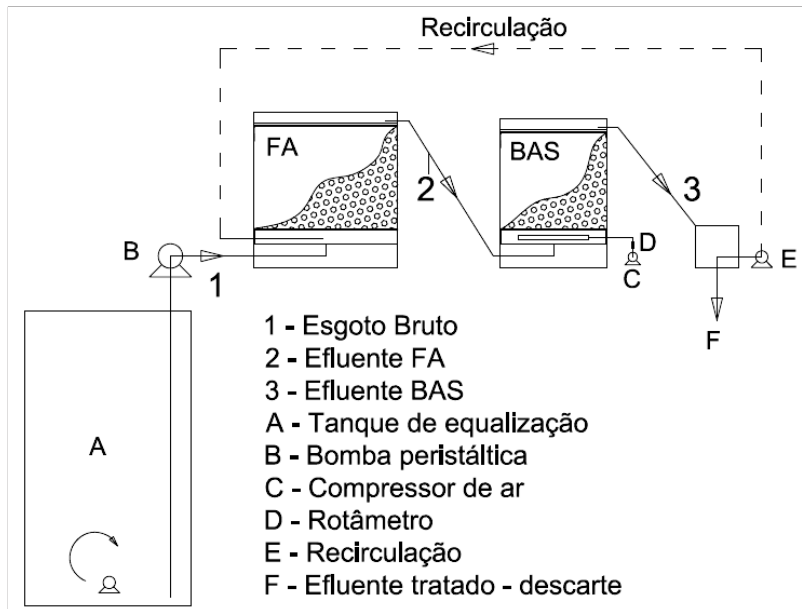

Fonte: Autor.

O sistema em questão esteve em operação por 207 dias antes de iniciar este estudo. Na etapa 1 buscou-se inibir a nitrificação no BAS, por meio da aplicação de TCO superior à $0,30 \mathrm{Kg}$ DBO $\mathrm{m}^{-3} \mathrm{~d}^{-1}$ (Tabela 2), a fim de comprovar condição desfavorável à conversão de nitrogênio; em seguida (etapa 2) verificar a conversão de compostos de nitrogênio com TCO de $0,30 \mathrm{Kg} \mathrm{DBO} \mathrm{m}^{-3} \mathrm{~d}^{-1}$, e, com o intuito de verificar o efeito positivo da recirculação sobre a nitrificação fez-se a recirculação do efluente do BAS para o FA na razão de $0,5(\mathrm{q} / \mathrm{Q})$ durante a $3^{\circ}$ etapa.

As concentrações DBO e OD no biofilme figuram como os principais requisitos para que a nitrificação ocorra de forma adequada (GONÇALVES et. al., 2001), desta forma adotou-se para a operação os valores relacionados na Tabela 2.

Tabela 2 - Condições desejáveis para a conversão de DBO e nitrificação no BAS

\begin{tabular}{llc}
\hline \multicolumn{1}{c}{ Parâmetros } & \multicolumn{1}{c}{ Unidade } & $\begin{array}{c}\text { Faixa de } \\
\text { Operação }\end{array}$ \\
\hline Carga orgânica aplicada ${ }^{(1)}$ & $\mathrm{kg} \mathrm{DQO} \mathrm{m}{ }^{-3} \cdot \mathrm{d}^{-1}$ & $0,5-1,0$ \\
Carga orgânica aplicada (2) & $\mathrm{kg} \mathrm{DBO} \mathrm{m}^{-3} \cdot \mathrm{d}^{-1}$ & $<0,30$ \\
Carga de amônia aplicada & $\mathrm{N}^{-N_{4}}{ }^{+} \cdot \mathrm{m}^{-3} \cdot \mathrm{d}^{-1}$ & $<0,20$ \\
Taxa de aeração & $\mathrm{Nm}^{3} \cdot \mathrm{kgDBO}^{-1}$ & $>60$ \\
TDH & $\mathrm{H}$ & $3,5-8,5$ \\
\hline
\end{tabular}

(1) Valores para conversão de N-amonical entre $50-70 \%$

(2) recomendação Tchobanoglous; Burton; Stensel (2003).

Fonte: adaptado de Mota e Von Sperling (2009).

Para o monitoramento e avaliação do desempenho do sistema o estudo foi dividido em três etapas, conforme indicado na Tabela 3.

A rotina de monitoramento compreendeu: $\mathrm{pH}$, alcalinidade, ácidos orgânicos voláteis (AOV), temperatura, demanda química de oxigênio (DQO), demanda bioquímica de oxigênio (DBO), oxigênio dissolvido (OD) e, série de nitrogênio com frequência semanal. As metodologias estão descritas no Standard Methods for the Examination of Water and Wastewater $20^{\text {th }}$ (APHA/AWWA/WEF, 1998).

Tabela 3 Condições operacionais: tempo de operação, vazão, TDH e TAS durante as etapas do estudo

\begin{tabular}{|c|c|c|c|c|c|c|c|c|c|}
\hline \multirow[t]{2}{*}{ Etapa } & \multirow{2}{*}{$\begin{array}{l}\text { Tempo de } \\
\text { operação } \\
\text { (d) }\end{array}$} & \multirow{2}{*}{$\begin{array}{l}\text { Período de } \\
\text { operação } \\
\text { (d) }\end{array}$} & \multicolumn{2}{|c|}{$\begin{array}{l}\text { Vazão } \\
\left(L h^{-1}\right)\end{array}$} & \multicolumn{3}{|c|}{$\begin{array}{c}\text { TDH } \\
\text { (h) }\end{array}$} & \multicolumn{2}{|c|}{$\begin{array}{c}\text { TAS } \\
\left(\mathrm{m}^{3} \mathrm{~m}^{-2} \mathbf{h}^{-1}\right) \\
\end{array}$} \\
\hline & & & $\mathbf{Q}$ & $\mathbf{q}$ & FA & BAS & SC & FA & BAS \\
\hline 1 & 83 & 208 a 291 & 3,62 & - & 9,0 & 4,9 & 13,9 & 32,5 & 58,8 \\
\hline 2 & 60 & 292 a 352 & 2,7 & - & 12,1 & 6,5 & 18,6 & 24,3 & 43,9 \\
\hline 3 & 56 & 353 a 409 & 2,7 & 1,35 & 12,1 & 6,5 & 18,6 & 36,4 & 65,8 \\
\hline
\end{tabular}

Fonte: Autor. 


\section{Resultados e Discussão}

Na Tabela 4 são apresentados os valores das variáveis de interesse na avaliação do esgoto bruto (EB), e efluentes do filtro anaeróbio (FA) e do biofiltro aerado submerso (BAS). A fim de evitar condições limitantes de OD, foram adotadas as recomendações verificadas em trabalhos recentes, nos quais as concentrações de OD menores que 3,5 mg $\mathrm{O}_{2} \mathrm{~L}^{-1}$ são insuficientes para manter o processo de nitrificação constante em reatores do tipo BAS, conforme Giustina (2009), Araújo Jr. e Zaiat (2009).
$\mathrm{Na}$ Figura 2, verifica-se que os valores de $\mathrm{pH}$ no BAS durante a etapa 1 foram 7,7 $\pm 0,2$, indicando que mesmo nos dias em que ocorreu uma discreta nitrificação, indicada pelo consumo de alcalinidade parcial (Figura 3), não foi suficiente para abaixar o pH. Não houve diferença significativa $(\mathrm{p}>0,05)$ no valor do $\mathrm{pH}$ de $7,3 \pm 0,3$, durante as etapas $2 \mathrm{e}$ 3. Evidenciando que, mesmo com, a ocorrência nitrificação, verificada por menores concentrações de nitrogênio amoniacal no efluente (Tabela 4), o $\mathrm{pH}$ permaneceu elevado, provavelmente devido ao stripping de $\mathrm{CO}_{2}$ que ocorre em reatores com elevada aeração, segundo Van Haandel e Lettinga (1994).

Tabela 4 - Valores das variáveis avaliadas nas 3 etapas.

\begin{tabular}{|c|c|c|c|c|c|c|c|c|c|c|c|c|}
\hline \multirow{3}{*}{ VARIÁVEL } & \multirow{3}{*}{ N } & \multicolumn{3}{|c|}{ Etapa 1} & \multicolumn{5}{|c|}{ Etapa 2} & \multicolumn{3}{|c|}{ Etapa 3} \\
\hline & & EB & FA & BAS & N & EB & FA & BAS & N & EB & FA & BAS \\
\hline & & \multicolumn{3}{|c|}{ MÉDIA \pm DE SVIO PADRÃO } & \multicolumn{5}{|c|}{ MÉDIA \pm DE SVIO PADRÃO } & \multicolumn{3}{|c|}{ MÉDIA — DE SVIO PADRÃO } \\
\hline pH & 11 & $6,6 \pm 0,6$ & $7,0 \pm 0,2$ & $7,7 \pm 0,2$ & 12 & $6,6 \pm 0,5$ & $7,1 \pm 0,2$ & $7,3 \pm 0,3$ & 14 & $6,8 \pm 0,3$ & $7,2 \pm 0,1$ & $7,3 \pm 0,5$ \\
\hline Temp. $\left(\mathrm{C}^{\circ}\right)$ & 11 & $25 \pm 2$ & $25 \pm 2$ & $25 \pm 2$ & 12 & $22 \pm 2$ & $21 \pm 2$ & $21 \pm 3$ & 14 & $21 \pm 2$ & $21 \pm 2$ & $21 \pm 1$ \\
\hline $\mathrm{OD}(\mathrm{mg} / \mathrm{L})$ & 10 & - & - & $5,0 \pm 0,7$ & 12 & - & - & $5,9 \pm 0,9$ & 14 & - & - & $6,1 \pm 0,5$ \\
\hline $\begin{array}{c}\mathrm{AOV} \\
\text { (mg HAc/L) }\end{array}$ & 11 & $237 \pm 82$ & $104 \pm 74$ & $49 \pm 20$ & 12 & $244 \pm 61$ & $79 \pm 36$ & $32 \pm 9$ & 14 & $234 \pm 55$ & $73 \pm 25$ & $32 \pm 8$ \\
\hline $\begin{array}{c}\mathrm{AP} \\
(\mathrm{mg} \mathrm{CaCO} / \mathrm{L})\end{array}$ & 11 & $62 \pm 49$ & $174 \pm 41$ & $175 \pm 19$ & 12 & $76 \pm 35$ & $197 \pm 21$ & $87 \pm 60$ & 14 & $93 \pm 42$ & $194 \pm 40$ & $76 \pm 78$ \\
\hline $\begin{array}{c}\text { AT } \\
\left(\mathrm{mg} \mathrm{CaCO}_{3} / \mathrm{L}\right)\end{array}$ & 11 & $212 \pm 36$ & $281 \pm 35$ & $238 \pm 21$ & 12 & $231 \pm 20$ & $293 \pm 23$ & $122 \pm 79$ & 14 & $249 \pm 48$ & $268 \pm 54$ & $98 \pm 97$ \\
\hline $\mathrm{DQO}\left(\mathrm{mg} \mathrm{O}_{2} / \mathrm{L}\right)$ & 11 & $713 \pm 287$ & $217 \pm 75$ & $70 \pm 23$ & 12 & $843 \pm 141$ & $256 \pm 94$ & $61 \pm 7$ & 14 & $646 \pm 133$ & $169 \pm 39$ & $60 \pm 12$ \\
\hline $\mathrm{DBO}\left(\mathrm{mg} \mathrm{O}_{2} / \mathrm{L}\right)$ & 8 & $411 \pm 200$ & $101 \pm 56$ & $17 \pm 15$ & 5 & $413 \pm 118$ & $85 \pm 26$ & $15 \pm 5$ & 4 & $381 \pm 62$ & $59 \pm 16$ & $15 \pm 11$ \\
\hline NTK (mg N/L) & 4 & $58 \pm 14$ & $64 \pm 11$ & $54 \pm 4$ & 5 & $66 \pm 1$ & $71 \pm 1$ & $34 \pm 14$ & 4 & $68 \pm 5$ & $59 \pm 10$ & $22+10$ \\
\hline $\mathrm{NH}_{4}{ }^{+}(\mathrm{mg} \mathrm{N} / \mathrm{L})$ & 9 & $56 \pm 9$ & $63 \pm 9$ & $52 \pm 6$ & 12 & $57 \pm 6$ & $62 \pm 6$ & $28 \pm 13$ & 14 & $58 \pm 7$ & $50 \pm 9$ & $22 \pm 10$ \\
\hline $\mathrm{NO}_{2}^{-}(\mathrm{mg} \mathrm{N} / \mathrm{L})$ & 5 & - & $0,01 \pm 0,01$ & $2,23 \pm 2,68$ & 10 & - & $0,01 \pm 0,00$ & $9,89 \pm 5,37$ & 14 & - & $0,01 \pm 0,00$ & $1,01 \pm 1,62$ \\
\hline $\mathrm{NO}_{3}^{-}(\mathrm{mg} \mathrm{N} / \mathrm{L})$ & & - & $0,1 \pm 0,2$ & $3,4 \pm 4,1$ & 10 & - & $0,10 \pm 0,00$ & $22,0 \pm 11,9$ & 14 & - & $0,80 \pm 0,60$ & $19,6 \pm 15,0$ \\
\hline
\end{tabular}

Fonte: Autor.

Figura 2 - Valores de $\mathrm{pH}$ do esgoto bruto e dos efluentes das unidades do sistema

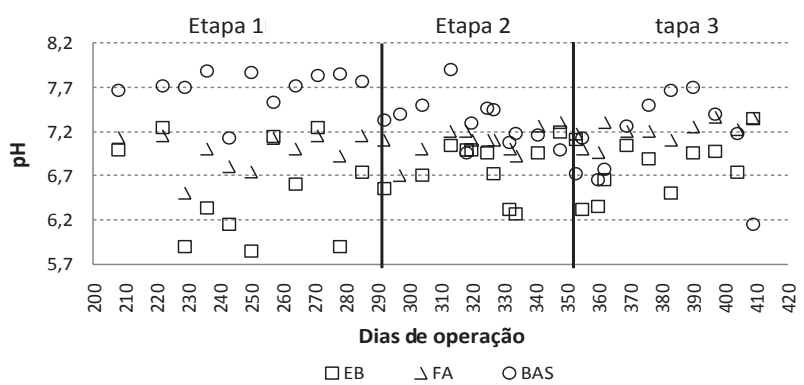

Fonte: Autor.
Com relação a alcalinidade ocorreu o esperado, de forma que os parâmetros adotados para que houvesse oxidação de nitrogênio amoniacal em torno de 50 a $70 \%$, foram alcançados sem necessidade de adição de um alcalinizante externo, pois mantendo um valor de alcalinidade residual em torno de $50 \mathrm{mg}$ $\mathrm{CaCO}_{3} \mathrm{~L}^{-1}$ (VAN HAANDEL; LETTINGA, 1994), não provocou uma redução significativa no valor do $\mathrm{pH}$. Contudo, o valor de $\mathrm{pH}$ diminuiu somente quando a alcalinidade foi extinta no $409^{\circ}$ dia de operação (Figura 3), provocado pela oxidação de $85 \%$ do nitrogênio amoniacal aplicado no BAS. 
Figura 3 - Valores de alcalinidade parcial durante as 3 etapas

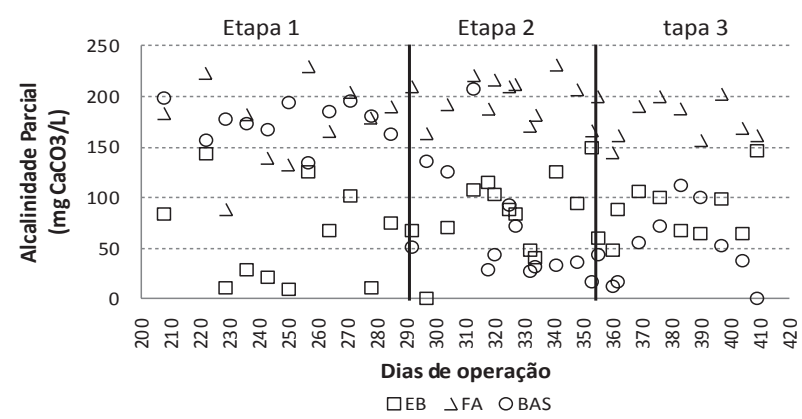

Fonte: Autor.

A estabilidade decorrente da presença do sistema tampão no FA foi indicada pela elevação nos valores da alcalinidade em relação aos valores obtidos para o esgoto bruto (Figuras 3) e pela manutenção de baixos valores de AOV durante as etapas, mesmo com grandes variações de concentração afluente (Figura 4). É possível notar que a recirculação permitiu obter menores concentrações de AOV no efluente do FA durante a etapa 3.

As concentrações de AOV no BAS mantiveramse muito baixas, com médias durante as etapas 2 e 3 de $32 \pm 9$ e $32 \pm 8$ mg HAc. $\mathrm{L}^{-1}$, respectivamente. Segundo Ono (2007), a nitrificação só ocorre após o completo consumo de AOV.

Figura 4 - Valores de ácidos orgânicos voláteis durante as 3 etapas

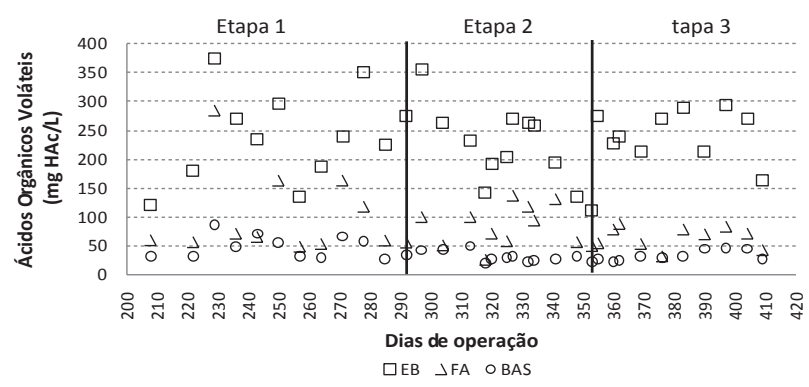

Fonte: Autor.
Os valores médios de TCO, em termos de DBO, aplicada e removida no BAS durante a etapa 1 foram $0,49 \pm 0,27$ e $0,41 \pm 0,29 \mathrm{~kg}^{\mathrm{DBO}} \mathrm{m}^{-3} \mathrm{~d}^{-1}$ (Figura 5-A). Durante a etapa 2, foram 0,31 \pm 0,08 e $0,26 \pm 0,09 \mathrm{~kg}$ DBO $\mathrm{m}^{-3} \mathrm{~d}^{-1}$ (Figura 5-B), e, $0,29 \pm 0,02$ e $0,21 \pm 0,08 \mathrm{~kg}$ DBO m $\mathrm{m}^{-3} \mathrm{~d}^{-1}$ durante etapa 3. Verifica-se que a recirculação possibilitou a operação do BAS abaixo do limite considerado adequado de taxa de carregamento orgânico em DBO de 0,30 kg DBO m $\mathrm{m}^{-1}$ (Figura 5-C).

Figura 5 - Correlação entre os valores da TCO, como DBO, aplicada e removida no BAS
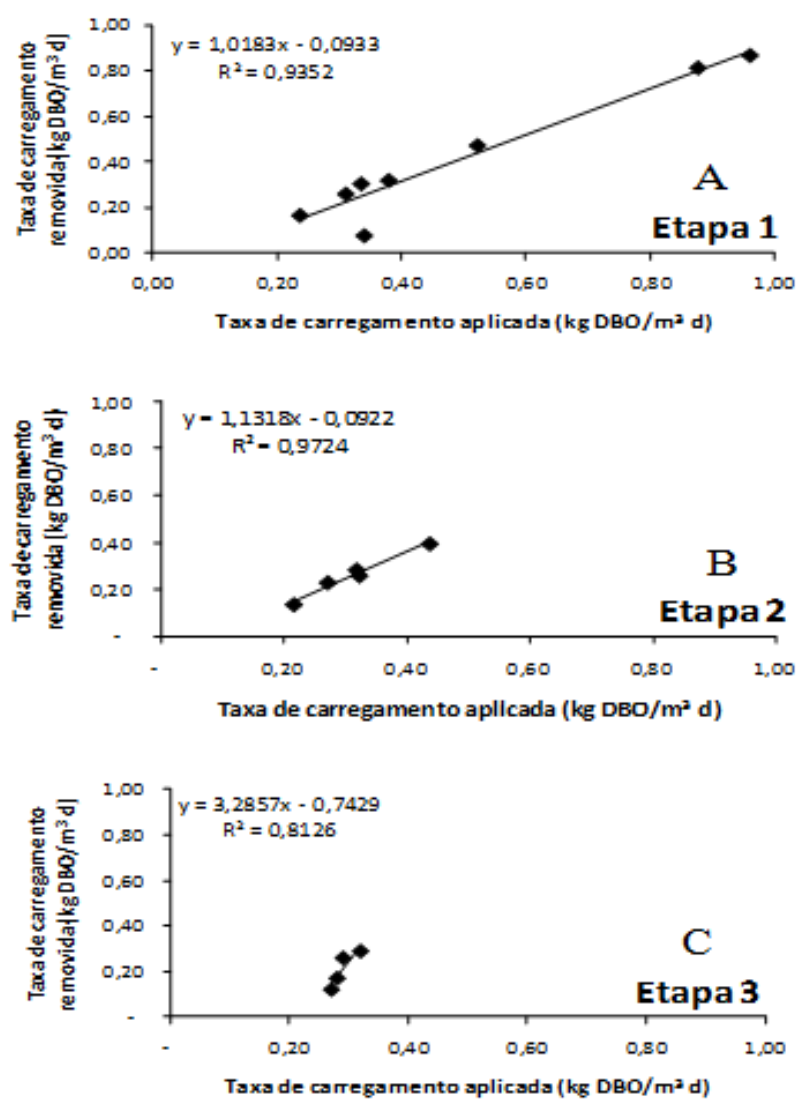

Fonte: Autor.

O teste de comparação de médias com relação à DBO mostra que a TCO aplicada e removida no FA durante 2 e 3 não diferiram significativamente entre si $(\mathrm{p}>0,05)$, que a TCO aplicada e removida no BAS durante 2 foram significativamente maiores 
que durante $3(\mathrm{p}<0,05)$, e que tanto a TCO aplicada e removida no $\mathrm{SC}$ não diferiram significativamente durante 2 e $3(p>0,05)$.

Verifica-se desta forma que a redução de DBO tanto no FA, como no BAS e no sistema como um todo não sofreu influência da existência ou não de recirculação do efluente, indicando que a operação do sistema de tratamento na configuração proposta está adequada a atender as expectativas sobre sua robustez e possibilidade de reduzir concentrações de carbono orgânico e compostos de nitrogênio.

$\mathrm{Na}$ Figura 6, apresentam-se as concentrações de Nitrogênio Total (NT) para esgoto bruto (EB), efluentes das unidades FA e BAS.

Figura 6 - Concentração média das diversas formas de nitrogênio

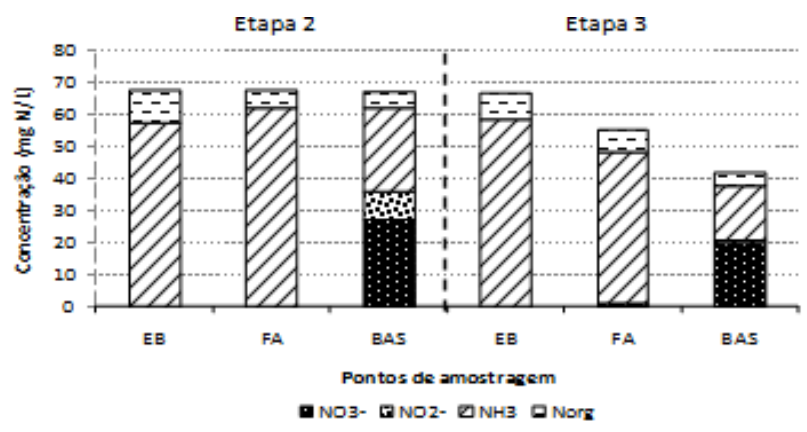

Fonte: Autor.

Observando a Figura 6 e Figura 7 na qual estão as porcentagens de remoção de Nitrogênio Total durante as etapas 2 e 3, verifica-se que durante 2 houve apenas a transformação das espécies de nitrogênio, associada à demanda para síntese celular e/ou retenção de nitrogênio orgânico. Porém durante 3 verifica-se que ocorreu redução de Nitrogênio Total presente na fase líquida, possivelmente associada a uma discreta atividade desnitrificante.
Figura 7 - Redução de Nitrogênio Total nas unidades, (FA) filtro anaeróbio, (BAS) biofiltro aerado submerso e (SC) sistema combinado

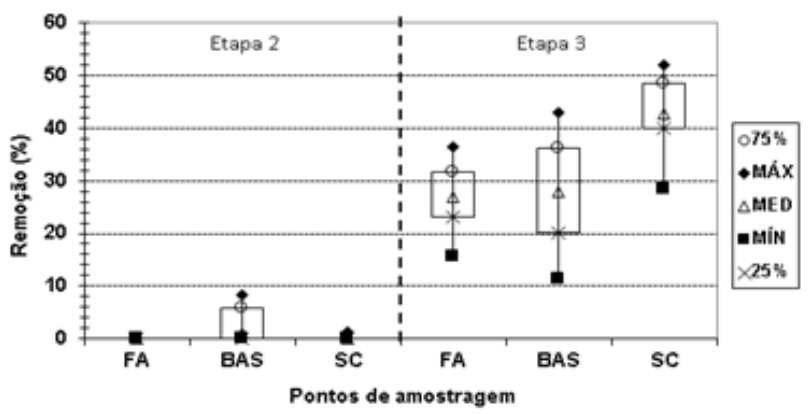

Fonte: Autor.

A redução da concentração de Nitrogênio Total alcançada no efluente do sistema foi de $43 \pm 10 \%$, operado com razão de recirculação de 0,5 .

Os valores obtidos para alcalinidade consumida foram próximos aos encontrados na literatura, que variam entre 7,1 a 7,2 $\mathrm{mg} \mathrm{CaCO}_{3} / \mathrm{mg} \mathrm{N}-\mathrm{NH}_{4}^{+}$, segundo Tchobanoglous; Burton; Stensel (2003), Villaverde, García-Encina e Fdz-Polanco (1997) e Scheible et al., 1993. Contudo, o valor de 8,23 g $\mathrm{CaCO}_{3} / \mathrm{g} \mathrm{N}^{-\mathrm{NO}_{4}^{+}}$foi encontrado por Giustina (2009). Segundo Christensen e Characklis (apud VILLAVERDE; GARCÍA-ENCINA; FDZPOLANCO, 1997) afirmam que o elevado consumo da alcalinidade em processos com biomassa aderida é devido à acumulação de carbonatos pouco solúveis dentro do biofilme.

Cabe salientar, segundo Biesterfeld et al. (2003) a taxa de nitrificação depende da concentração de carbono inorgânico (isto é, alcalinidade bicarbonato) sugerindo que o mínimo requerimento de alcalinidade é função da necessidade de carbono para síntese celular e não necessariamente refere-se a requerimentos de neutralização de acidez gerados pelo processo de nitrificação.

$\mathrm{Na}$ Figura 8 estão apresentadas as taxas de nitrificação (TN) durante 2 e 3 , operando sem e com recirculação do efluente nitrificado no BAS para o FA. 
Figura 8 - Taxas de nitrificação operando sem e com recirculação.

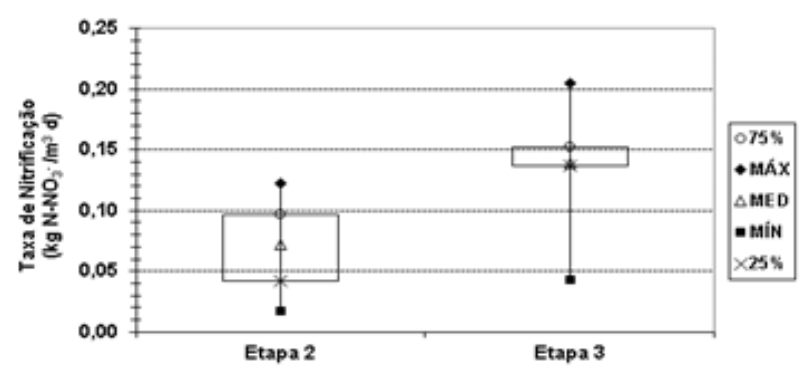

Fonte: Autor.

Verifica-se que houve um efeito positivo da recirculação sobre as taxas de nitrificação obtidas, elevando a taxa de nitrificação de $0,10 \pm 0,05$ para $0,17 \pm 0,02 \mathrm{~kg} \mathrm{~N}-\mathrm{NO}_{3}-\mathrm{m}^{-3} \mathrm{~d}^{-1}$.

Del Pozo e Diez (2005) sugerem que se deve levar em consideração que importantes liberações de amônia a partir da lise da biomassa podem tornar a real taxa de nitrificação maior que a calculada a partir do balanço de massa.

\section{Conclusões}

A aplicação de taxas de carregamento orgânico no BAS, superiores a $0,30 \mathrm{~kg}$ DBO $\mathrm{m}^{-3} \mathrm{~d}^{-1}$ desfavorecem a nitrificação.

A redução da concentração de Nitrogênio Total alcançada no efluente do sistema foi de $43 \pm$ $10 \%$, operado com razão de recirculação de 0,5 , provavelmente o aumento da recirculação permitirá maiores remoções de NT.

Verifica-se desta forma que a redução de DBO tanto no FA, como no BAS e no sistema como um todo não sofreu influência da existência ou não de recirculação do efluente, indicando que a operação do sistema de tratamento na configuração proposta está adequada a atender as expectativas sobre sua robustez e possibilidade de reduzir a demanda bioquímica de oxigênio e de compostos de nitrogênio no efluente.

\section{Referências}

ARAUJO JUNIOR, M. M.; ZAIAT, M. (2009). Upflow fixed-bed anaerobic-aerobic reactor for removal of organic matter and nitrogen from L-Lysine plant wastewater. Canadian Journal of Civil Engineering (Print), Canada: NRC Research Press. v. 36, p. 1085-1094.

APHA/AWWA/WEF - American Public Health Association/American Water Works Association/ Water Environment Federation (1998) Standard Methods for the Examination of Water and Wastewater. 20th Edition. New York: APHA.

BIESTERFELD, S., FARMER, G., RUSSELL, P., FIGUEROA, L. (2003). Effect of alkalinity type and concentration on nitrifying biofilm activity. Water Environment Research, New York: JSTOR, v. 75, n. 3, p. 196-204.

DEL POZO, R.; DIEZ, V. (2005). Integrated anaerobic-aerobic fixed-film reactor for slaughterhouse wastewater treatment. Water Research, Philadelphia: Elsevier Inc. v. 39, p. 1114-1122.

GIUSTINA, S.V.D. (2009). Remoção biológica de nitrogênio utilizando biofiltro aerado submerso multi-estágio. Dissertação (Mestrado em Recursos Hídricos e Saneamento Ambiental) - Universidade Federal do Rio Grande do Sul, Porto Alegre. 161 p.

GONÇALVES, R.F.; CHERNICHARO, C.A.L.; ANDRADE NETO, C.O.; SOBRINHO, P.A.; KATO, M.T.; COSTA, R.H.R.; AISSE, M.M.; ZAIAI, M. (2001) Pós-tratamento de efluentes de reatores anaeróbios por reatores de biofilme. In: CHERNICHARO, C.A.L. (Coord.) Póstratamento de efluentes de reatores anaeróbios. Belo Horizonte: Projeto PROSAB 2, p. 171-278.

HAGOPIAN, D. S.; RILEY, J. G. (1998). A closer look at the bacteriology of nitrification. Aquacultural Engineering. Philadelphia: Elsevier Inc. v. 18, p. 223-244, 1998. 
MOTA, S. \& VON SPERLING, M. (2009) Nutrientes de esgoto sanitário: utilização e remoção. vol. 1. Rio de Janeiro: PROSAB/FINEP. $430 \mathrm{p}$.

ONO,A. F. (2007). Desenvolvimento e comparação de estratégias de operação de reatores aeróbio/ anóxico operados em batelada sequencial para remoção de nitrogênio de água residuária de indústria química. Dissertação (Mestrado em Hidráulica e Saneamento) - Escola de Engenharia de São Carlos, Universidade de São Paulo, São Carlos, 113 p.

SCHEIBLE, O.K.; MULBARGER, M.; SUTTON, P.; SIMPKIN, T.; DAIGGER, G. (1993) Nitrogen Control Manual EPA/625/R-93/010. Lancaster: Technomic Pub. Co. 311 p.

TCHOBANOGLOUS, G.; BURTON, F.L.; STENSEL, H.D. (2003) Wastewater Engineering: treatment and reuse. New York: McGraw-Hill. 1819 p.

VAN HAANDEL, A. C.; LETTINGA, G. (1994) Tratamento anaeróbio de esgotos: um manual para regiões de clima quente. Campina Grande: Epgraf. 240 p.

VILLAVERDE, S.; GARCÍA-ENCINA, P. A.; FDZ-POLANCO, F. (1997). Influence of $\mathrm{pH}$ over nitrifying biofilm activity in submerged biofilters. Water Research, Printed in Great Britain, v. 31, n. 5, p. 1180-1186.

Recebido em 27 Setembro, 2012 - Received on September 27, 2012.

Aceito em 6 Maio, 2014 -Accepted on May 6, 2014. 